\title{
Scandal rocks nuclear power industry in West Germany
}

\section{Munich}

A BRIBERY scandal linked to the illegal shipment and storage of nuclear waste has dealt a serious blow to the image of West Germany's nuclear power industry. And after a year's lull, the question of longterm storage sites for nuclear waste has once again taken centre stage.

West Germany's centre-right coalition government seemed to have outlasted the intense anti-nuclear sentiment generated by the Chernobyl catastrophe (see Nature 321, 640; 1986). But the current scandal has provided ammunition to those in West Germany who believe that it is not possible to run a safe nuclear programme.

The scandal began in early December when bribery charges were brought against employees of the nuclear waste transport firm Transnuklear, located in the city of Hanau. One of the employees committed suicide in prison after admitting his guilt.

The affair began to loom larger when, on 17 December, it was revealed that Transnuklear had shipped more than 350 barrels of radioactive waste under false labels to temporary storage sites in West Germany. The waste was intended to be processed in a Belgian nuclear energy centre and returned.

Mislabelled barrels began turning up all over the country and the numbers grew day after day throughout the Christmas

\section{New AIDS committee in France - the buck stops here?}

Paris

To stem what is perceived as a proliferation of competing organizations, committees and charities concerned with AIDS (acquired immune deficiency syndrome), the Institut Pasteur and the Fondation pour la Recherche Médicale (FRM) have announced yet another - the Comité National pour la Recherche sur le SIDA.

The reasoning behind this seemingly paradoxical move, according to Mr CoursMach of the FRM, is "to ensure the best possible national coordination for distributing donations from the public, while providing donors with an assurance that the money will be well-spent". The committee, whose executive council is drawn equally from the Pasteur and FRM's scientific advisory council, will select applications for funding "on the basis of scientific or humanitarian merit" and will, through its membership, ensure coordination with state-supported research.

The association with the Pasteur Institute is also a tactical step towards the creation of a National AIDS Research Foundation. The new foundation should provide a more visible target for fundraising and, according to CoursMach, "ensure the centralization of funds and avoid a dispersion of donations".

The FRM, France's largest medical charity, was chosen by the government as the focus for a national fund-raising drive last June and has already distributed FF10 million ( $£ 1$ million) to research groups including the Pasteur itself - and to smaller voluntary bodies.

Coming so soon after the creation of two other AIDS foundations associated with the Pasteur Institute - the French and American AIDS Foundation and the
World AIDS Foundation (see Nature 330 , 507 ; 1987) - the announcement of the new committee caused some initial confusion. "The idea", explained Dr Caroline Chaine of the Pasteur Institute, "is to rationalize the work of different associations, whether private or state-funded, and help them to be more effective, while respecting their independence". "The number of AIDS foundations and committees is confusing", admitted Chaine, "but this should be the last one for quite some time."

\section{Paris}

- Latest World Health Organisation (WHO) figures suggest that the number of known cases of AIDS in France increased from 1,980 at the end of June 1987 to 2,523 at the end of September - an increase of 25 per cent. This means that France has the second highest proportion of declared AIDS sufferers in the world, after the United States, which had 45,436 known cases on 9 November. Britain had 1,123 cases.

Danielle Mitterrand, wife of the French President, and founder of FranceLibertés, a charitable organization aimed at promoting civil and human rights, recently called attention to the cultural and financial barriers to AIDS prevention in some African countries. In a letter to Mitterrand pointed to the inadequacy of AIDS antibodies and severe obstacles, both financial and logistical, to effective educational campaigns.

In the same issue of Le Monde, it was pointed out that a pack of condoms cost the equivalent of a day's salary in some parts of East and Central Africa. the daily newspaper, Le Monde, Mme resources for screening blood supplies for holidays. The Environment Ministry's latest count has reached 1,900 barrels. It was also discovered that 321 of the barrels were contaminated with traces of plutonium and cobalt -60 .

Environment Minister Klaus Töpfer (Christian Democrat or CDU) has been hard-pressed to keep up with the revelations. A 'working group' of representatives of the Environment Ministry and the Länder (states) last week recommended stricter regulation of the nuclear waste transport industry. Most urgent is the need to transfer the oversight of the industry to the federal level; four different authorities at present regulate the transport of various radioactive materials.

Chancellor Helmut Kohl (CDU) recognized the need for damage control on 7 January when he criticized Transnuklear employees for their improper behaviour. But this attempt to limit the political consequences of the scandal seems to be too little, too late. There are reports of a considerable loss of public trust in the government and the nuclear industry. Green Party Bundestag member Barbara Rust said that public disapproval of the continued reliance on nuclear power - measured at up to 70 per cent according to independent surveys in late 1987 - "can only go higher". The latest focus is on so-called 'permanent storage' (Endlager) for nuclear waste of all types. Nowhere in the world is there a site that opponents of nuclear power think secure enough for the storage of used nuclear fuel elements, which contain plutonium and other highly radioactive substances.

Construction on the proposed West German site, located at the former salt mine of Gorleben, was halted after a fatal accident in May last year and will not begin again until the spring.

If it should not prove feasible to complete the Gorleben site, the government announced on 7 January that it would eventually propose another site. Werner Herud of the federal agency responsible for preparing waste storage sites, the Physikalische Technische Bundesanstalt, said that all the alternatives are located in nearby salt beds. But some scientists have long argued that salt is an inappropriate medium for waste storage. Controversy has also arisen about the proposed storage site for low- and middleradioactive waste, known as Schacht Konrad, which is also based on salt

Even if all West Germany's nuclear power plants were shut off immediately, there would still be a problem of what to do with the waste. Until now, spent West German fuel elements have been stored at the French facility at Cap La Hague; beginning in 1993, however, they are scheduled to return. The question is, will there be some place to put them?

Steven Dickman 